\title{
Possible protection by inhaled budesonide against ischaemic cardiac events in mild COPD
}

\author{
C-G. Löfdahl*, D.S. Postma* ${ }^{\#}$, N.B. Pride`, J. Boe ${ }^{+}$and A. Thorén ${ }^{\S}$
}

ABSTRACT: Epidemiological studies have indicated that chronic obstructive pulmonary disease (COPD) may be associated with an increased incidence of ischaemic cardiac events.

The current authors performed a post hoc analysis of the European Respiratory Society's study on Chronic Obstructive Pulmonary Disease (EUROSCOP); a 3-yr, placebo-controlled study of an inhaled corticosteroid budesonide $800 \mu \mathrm{g} \cdot$ day $^{-1}$ in smokers (mean age 52 yrs) with mild COPD. The current study evaluates whether long-term budesonide treatment attenuates the incidence of ischaemic cardiac events, including angina pectoris, myocardial infarction, coronary artery disorder and myocardial ischaemia.

Among the 1,175 patients evaluated for safety, 49 (4.2\%) patients experienced 60 ischaemic cardiac events. Patients treated with budesonide had a significantly lower incidence of ischaemic cardiac events (18 out of 593; $3.0 \%$ ) than those receiving placebo (31 out of $582 ; 5.3 \%$ ).

The results of the present study support the hypothesis that treatment with inhaled budesonide reduces ischaemic cardiac events in patients with mild chronic obstructive pulmonary disease.

\section{KEYWORDS: Budesonide, chronic obstructive pulmonary disease, ischaemic cardiac events}

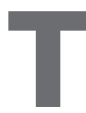
obacco smoking is one of the major causative agents for a number of morbidities, such as chronic obstructive pulmonary disease (COPD), cardiovascular disease and lung cancer. COPD affects $\sim 600$ million people [1], and the mortality from COPD continues to increase. By 2020 it is expected to be the third largest cause of death worldwide [2]. The relentless progression of COPD leads to an increasing loss of lung function, increased symptoms and deteriorating health-related quality of life. Exacerbations have been identified as one key driver of this progression and are a major independent factor of poor prognosis and death in COPD [3]. Recent studies have indicated that COPD also has a considerable systemic inflammatory component [4-6]. Furthermore, a reduced lung function and COPD are independent risk factors for cardiovascular morbidity and mortality [7-9].

Current guidelines for the management of COPD recommend the use of an inhaled corticosteroid (ICS) alongside a long-acting bronchodilator to prevent acute exacerbations in patients with severe COPD [2, 10-12]. Furthermore, retrospective analyses and a meta-analysis reported that ICS reduce the number of hospitalisations and the overall mortality rate associated with COPD
$[6,13-15]$. Next to effects on exacerbations in COPD, there is suggestive evidence that ICS reduce elevated C-reactive protein (CRP) levels [16-18], a marker of inflammation that is associated with reduced lung function [19-22] and ischaemic cardiac disease [23].

Based on the previously mentioned findings, the current authors performed a post hoc analysis of the European Respiratory Society's study on Chronic Obstructive Pulmonary Disease (EUROSCOP) [24] to investigate whether longterm budesonide treatment $\left(800 \mu \mathrm{g} \cdot \mathrm{day}^{-1}\right)$ attenuates the incidence of ischaemic cardiac events, such as angina pectoris and myocardial infarcof ischaemic cardiac disease at inclusion. The EUROSCOP study was not designed for assessment of exacerbations; therefore, a well-recognised surrogate marker for severe exacerbations, courses of oral corticosteroids, was analysed in order to explore any association of acute exacerbations with ischaemic cardiac events.

\section{METHODS}

The EUROSCOP study was a 3-yr, double-blind, randomised, multicentre, placebo-controlled study of budesonide (Pulmicort ${ }$ administered via Turbuhaler®; AstraZeneca, Södertälje, Sweden.) tion, in patients with mild COPD and a low rate

\section{AFFILIATIONS}

*Dept of Respiratory Medicine and Allergology, Lund University, and ${ }^{\S}$ AstraZeneca R\&D, Lund, Sweden.

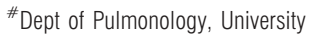
Medical Center Groningen, University of Groningen, Groningen, The Netherlands.

"Dept of Thoracic Medicine, National Heart and Lung Institute, Imperial College, London, UK. ${ }^{+}$Dept of Respiratory Diseases, National Hospital Rikshospitalet, University of Oslo, Oslo, Norway.

CORRESPONDENCE

C-G. Löfdahl

Dept of Respiratory Medicine and Allergology University Hospital SE-22185 Lund Sweden

Fax: 4646146793

E-mail: claes-goran.lofdahl@ med.lu.se

Received:

October 032006

Accepted after revision:

February 162007

STATEMENT OF INTEREST

Statements of interest for all authors can be found at www.erj.ersjournals.com/misc/ statements.shtml 
$800 \mu \mathrm{g} \cdot$ day $^{-1}$ in current smokers with mild COPD. The study was conducted in nine Western European countries.

\section{Patients}

Patient inclusion criteria have been reported previously [24]. In brief, current smokers (at least 5 cigarettes $\cdot$ day $^{-1}$ ) were included who had: 1) smoked for $\geqslant 10$ yrs or had a smoking history of at least 5 pack-yrs; 2) a post-bronchodilator forced expiratory volume in one second (FEV1) of $50-100 \%$ of the predicted normal value; 3 ) a ratio of pre-bronchodilator FEV1 to slow vital capacity of $<70 \%$; and 4 ) a reversibility of FEV1 with $1 \mathrm{mg}$ inhaled terbutaline of $<10 \%$ (as FEV1\% pred). The following patients were excluded from the study: patients with a history of asthma, allergic rhinitis or allergic eczema; patients with a concomitant disease that could interfere with the interpretation of the study; patients who used $\beta$-receptor antagonists; and patients who had used oral glucocorticoids for $>4$ weeks during the preceding 6 months.

\section{Study assessments}

A hypothesis-based post hoc analysis was performed using the 3-yr safety database from the EUROSCOP study. The following adverse events and serious adverse events, as spontaneously reported by the responsible physician, were considered relevant in the analysis of the incidence of ischaemic cardiac events: 1) angina pectoris; 2) myocardial infarction; 3) coronary artery disorder; and 4) myocardial ischaemia. These are the preferred terms from the Adverse Event dictionary used in the trial (AstraAED, based on World Health Organization Adverse Reaction Terminology). A verbatim term reported by the investigator (e.g. coronary insufficiency) is coded in the dictionary to the included term with closest resemblance to the reported term (ischaemic heart disease), which belongs to the corresponding preferred term (coronary artery disorders) used in the study report. Baseline demographic and disease characteristic data of the overall study population was compared with that of the population experiencing any ischaemic cardiac adverse event in order to identify any potential prognostic factor. This included an analysis of courses of oral corticosteroids as a surrogate marker for severe exacerbations. Patients were followed for 3 yrs.

\section{Statistical analyses}

All analyses were conducted using the safety population. Descriptive statistics are presented for the baseline demographic and disease characteristics comparison. The incidence of the pre-defined first-time ischaemic cardiac adverse events was compared among patients receiving budesonide and those receiving placebo using the Chi-squared test. The total number of ischaemic cardiac events and the total number of courses of oral corticosteroids was compared between groups using Poisson regression with time in the study as an offset variable. A Kaplan-Meier survival analysis was also performed.

\section{RESULTS}

Out of a total of 1,277 randomised patients, 1,275 were included in the intention-to-treat analysis. No data point regarding safety was collected for 100 of these patients and they were not considered evaluable for safety according to current database rules. Therefore, 1,175 patients were included in the safety evaluation (budesonide $n=593$, placebo $n=582$ ).
The baseline demographics and disease characteristics of the study population have been reported elsewhere [24] and were comparable between the treatment groups, as were the total number of treatment years, the discontinuations due to adverse events and the reasons for discontinuations. Among the 1,175 evaluated patients, 132 were discontinued due to an adverse event (70 budesonide, 62 placebo) and 131 were discontinued due to other reasons ( 65 budesonide, 66 placebo).

At baseline, 32 (2.7\%; 15 on budesonide, 17 on placebo) patients had a previous medical history of ischaemic cardiac events. Among these 32 patients, four developed an ischaemic cardiac event during the trial (one budesonide, three placebo). During the study, there were 18 deaths (eight budesonide versus 10 placebo). Of these, three were due to myocardial infarctions (two budesonide versus one placebo). The most common cause of death was pulmonary carcinoma (three budesonide versus three placebo). Only one case of death was "unspecified" and reported as "sudden death" (placebo).

\section{Incidence of ischaemic cardiac events}

In total, $49(4.2 \%)$ patients had a total of 60 ischaemic cardiac events. As stated previously, three patients died due to myocardial infarction and no other deaths occurred among the 49 patients with ischaemic cardiac disease. Significantly fewer patients treated with budesonide (18 (3.0\%) out of 593) experienced at least one ischaemic cardiac event during the 3 yrs of the study compared with those who received placebo (31 $(5.3 \%)$ out of $582 ; p=0.048,95 \%$ confidence interval (CI): $-4.7--0.0 \%$ ). The 18 patients treated with budesonide experienced a total of 22 ischaemic cardiac events, while the 31 patients who received placebo experienced a total of 38 events. The Poisson regression analysis resulted in an estimated ratio of ischaemic cardiac event rate of 0.58 (95\% CI: $0.35-0.98$; $p=0.043$; fig. 1). As can be seen in figure 1 the specific events of angina pectoris, myocardial infarction and coronary artery disease are lower for budesonide. In addition to this observation, the overall incidence of ischaemic cardiac events was lower with budesonide than with placebo.

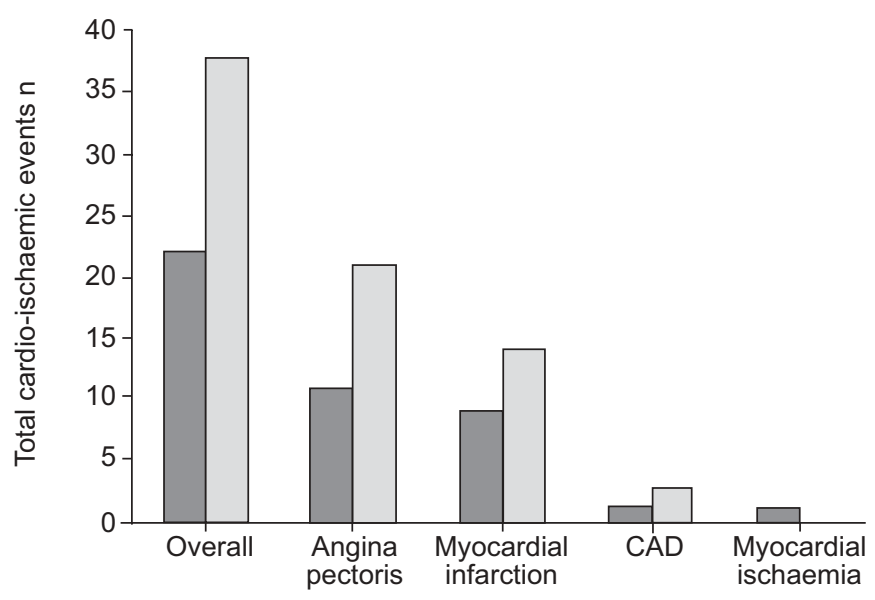

FIGURE 1. Distribution of ischaemic cardiac events among adult patients with chronic obstructive pulmonary disease randomised to receive budesonide $800 \mu \mathrm{g} \cdot$ day $^{-1}(\square)$ or placebo $(\square)$ for up to $3 \mathrm{yrs}$. CAD: coronary artery disease. 


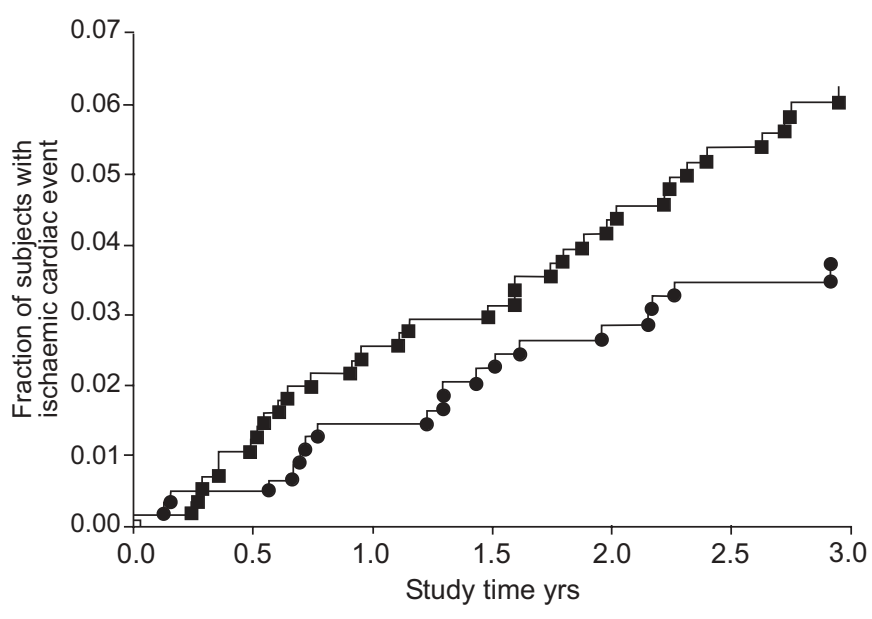

FIGURE 2. Kaplan-Meier survival analysis of the proportion of patients experiencing an ischaemic cardiac event during treatment with budesonide $800 \mu \mathrm{g} \cdot \mathrm{day}^{-1}(\mathbf{)})$ or placebo $(\square)$ for up to $3 \mathrm{yrs}$.

Kaplan-Meier survival analysis of the fraction of patients experiencing an ischaemic cardiac event showed a clear distinction between the budesonide and placebo groups (fig. 2).

Out of the 60 reported ischaemic cardiac events, 30 (budesonide $n=13$, placebo $n=17$ ) were serious (e.g. death, hospitalisation) and 30 (budesonide $n=9$, placebo $n=21$ ) were nonserious.

On the basis of these findings, the number needed to treat with budesonide to prevent one ischaemic cardiac event is 95 .

\section{Potential prognostic factors}

The baseline demographic and disease characteristics, including lung function measures and pack-yrs smoking, of the patients who experienced ischaemic cardiac events during the EUROSCOP study were similar to those of the overall population (table 1). The yearly rate of severe exacerbations (estimated from courses of oral corticosteroids) was reduced in the budesonide group versus placebo group by $37 \%$ ( 0.05 versus $0.07, \mathrm{p}=0.002)$, corresponding to a yearly exacerbation rate ratio of 0.63 (95\% CI $0.47-0.85)$. Among the 49 patients with ischaemic cardiac events, seven $(14 \%)$ received at least one course of oral corticosteroids compared with $8 \%$ in the remaining patients (nonsignificant).

\section{DISCUSSION}

Results of the post hoc analysis of data from the EUROSCOP study show that significantly fewer patients treated with budesonide $800 \mu \mathrm{g} \cdot$ day $^{-1}$ experienced ischaemic cardiac events than those who received placebo (18 versus 31, respectively; $p<0.05)$. Similar results were observed when the absolute number of events was compared between the two treatment groups: 22 events among budesonide-treated patients compared with 38 events among those who received placebo $(\mathrm{p}<0.05)$.

The difference in the incidence of first-time ischaemic cardiac event between patients treated with budesonide and those who received placebo was not a result of differences in baseline characteristics. These were similar in the two treatment groups and also similar to those of the overall patient population, as were the total number of treatment years, the discontinuations due to adverse events and the reasons for discontinuations. Of importance to the results is that the baseline prevalence of ischaemic cardiac events was low in the EUROSCOP study and that the overall mortality was lower than expected from reference populations [25]: 18 observed cases versus 34.4 cases $(p=0.0052)$.

At the time of the EUROSCOP study relatively little was known about the systemic component of COPD. Epidemiological studies have since indicated that COPD is not solely a disease of the respiratory tract but may also involve the cardiovascular system, resulting in an increased incidence of cardiovascular events $[7,8,26]$. The cause behind the association between COPD and cardiovascular disease is still unknown but one explanation could be that the systemic inflammation in COPD increases the risk for cardiovascular events. Elevated CRP levels, a marker of inflammation that is associated with reduced lung function, are also associated with ischaemic cardiac disease [23]. Thus, it would be plausible that inhaled steroids, such as budesonide, reduce the local inflammation and subsequent cardiovascular morbidity [27]. In this case, a local effect on the lung resulting in diminished spill-over of inflammation systemically to the cardiovascular

TABLE 1 Baseline demographics and disease characteristics of patients experiencing at least one ischaemic cardiac event compared with the overall study population

Parameter

Subjects $\mathbf{n}$

Males/females \%

Age yrs

Body mass index

Pack-yrs

FEV1 L

$\mathrm{FEV}_{1} \%$ pred

Inspiratory vital capacity L
Patients experiencing ischaemic cardiac events

Overall EUROSCOP study population

$\begin{array}{cc}49 & 1277 \\ 86 / 14 & 73 / 27 \\ 54.7(32-64) & 52.5(25-66) \\ 25.7(20-32) & 24.8(15-44) \\ 40(18-111) & 36(0-171) \\ 2.5(1.4-3.6) & 2.5(1.0-4.7) \\ 74.3(51-99) & 76.9(42-103) \\ 4.1(2.2-5.9) & 4.1(1.9-7.8)\end{array}$

Data are presented as mean (range), with the exception of pack-yrs, which is median (range), unless otherwise stated. EUROSCOP: The European Respiratory Society's Study on Chronic Obstructive Pulmonary Disease; FEV1: forced expiratory volume in one second; \% pred: \% predicted. 
system is an attractive hypothesis, since systemic steroids may have a dose-dependent harmful effect on the risk for ischaemic heart disease [28]. An alternative explanation may be that acute exacerbations of COPD may precipitate cardiovascular disease [29]. It has been shown that inhaled steroids reduce the rate of acute exacerbations in advanced COPD [30]. The EUROSCOP study was not designed for assessment of exacerbations but, using courses of oral corticosteroids as a surrogate marker, a reduction was seen corresponding to a yearly decrease of $37 \%$ in the budesonide group versus the placebo group $(p=0.0022)$. This study could not investigate whether exacerbations and ischaemic cardiac events were associated in this respect, since it did not have the power to reveal this, though there was a trend towards a higher frequency in those with ischaemic cardiac events.

When evaluating these results it is important to note that the EUROSCOP population was $\sim 10$ yrs younger than other similar studies in the field $[10,12,31,32]$. The population also had much milder disease, as the mean FEV1 was $76 \%$ pred normal compared with $36-50 \%$ in the studies mentioned previously. Thus, this study population represents a much earlier phase in the natural history of COPD than many comparable studies.

The dose-dependent risks of systemic corticosteroids for cardiac disease reported in an observational large study [28] and the general vulnerability of COPD patients given their high age and frequent comorbidity require a well-documented safety profile for any intervention. The design and duration of the 3-yr EUROSCOP study has provided a reassuring safety profile for long-term use of budesonide at a daily dose of $800 \mu \mathrm{g}[24,33]$.

The data presented here suggest that ischaemic cardiac events among patients with relatively mild chronic obstructive pulmonary disease could be significantly reduced by inhaled budesonide. Further studies are required to verify this finding and to study the mechanisms involved.

\section{ACKNOWLEDGEMENTS}

The authors acknowledge the great contribution to the EUROSCOP trial by R. Pauwels, too early deceased.

\section{REFERENCES}

1 World Health Organization. The World Health Report 1998. Life in the 21st Century. A vision for all. Geneva, World Health Organization, 1998.

2 Global Initiative for Chronic Obstructive Lung Disease. Global strategy for the diagnosis, management, and prevention of chronic obstructive pulmonary disease. Geneva, NHLBI/WHO report, 2005.

3 Soler-Cataluna JJ, Martinez-Garcia MA, Roman Sanchez P, Salcedo E, Navarro M, Ochando R. Severe acute exacerbations and mortality in patients with chronic obstructive pulmonary disease. Thorax 2005; 60: 925-931.

4 Agusti A. COPD, a multicomponent disease: implications for management. Respir Med 2005; 99: 670-682.

5 Sin DD, Man SF. Chronic obstructive pulmonary disease as a risk factor for cardiovascular morbidity and mortality. Proc Am Thorac Soc 2005; 2: 8-11.
6 Sin DD, Wu L, Man SF. The relationship between reduced lung function and cardiovascular mortality: a populationbased study and a systematic review of the literature. Chest 2005; 127: 1952-1959.

7 Dankner R, Goldbourt U, Boyko V, Reicher-Reiss H. Predictors of cardiac and non-cardiac mortality among 14,697 patients with coronary heart disease. Am J Cardiol 2003; 91: 121-127.

8 Engström G, Lind P, Hedblad B, et al. Lung function and cardiovascular risk. Relationship with inflammation-sensitive plasma proteins. Circulation 2002; 106: 2555-2560.

9 Anthonisen NR, Connett JE, Enright PL, Manfreda J. Hospitalizations and mortality in the Lung Health Study. Am J Respir Crit Care Med 2002; 166: 333-339.

10 Calverley PM, Boonsawat W, Cseke Z, Zhong N, Peterson S, Olsson H. Maintenance therapy with budesonide and formoterol in chronic obstructive pulmonary disease. Eur Respir J 2003; 22: 912-919.

11 Sin DD, Man SFP. Inhaled corticosteroids in the long-term management of patients with chronic obstructive pulmonary disease. Drugs Aging 2003; 20: 867-880.

12 Szafranski W, Cukier A, Ramirez A, et al. Efficacy and safety of budesonide/formoterol in the management of chronic obstructive pulmonary disease. Eur Respir J 2003; 21: 74-81.

13 Sin DD, Wu L, Anderson J, et al. Inhaled corticosteroids and mortality in chronic obstructive pulmonary disease. Thorax 2005; 12: 992-997.

14 Soriano JB, Kiri VA, Pride NB, Vestbo J. Inhaled corticosteroids with/without long-acting beta-agonists reduce the risk of rehospitalisations and death in COPD patients. Am J Respir Med 2003; 2: 67-74.

15 Tkacova $R$, Toth S, Sin DD. Inhaled corticosteroids and survival in COPD patients receiving long-term home oxygen therapy. Respir Med 2006; 100: 385-392.

16 Man SFP, Sin DD. Effect of corticosteroids on systemic inflammation in chronic obstructive pulmonary disease. Proc Am Thorac Soc 2005; 2: 78-82.

17 Pinto Plata VM, Müllerova $\mathrm{H}$, Toso JF, et al. C-reactive protein in patients with COPD, control smokers and nonsmokers. Thorax 2006; 61: 23-28.

18 Sin DD, Lacy P, York E, Man SF. Effects of fluticasone on systemic markers of inflammation in chronic obstructive pulmonary disease. Am J Respir Crit Care Med 2004; 170: 760-765.

19 Broekhuizen R, Wouters EF, Creutzberg EC, Schols AM. Raised CRP levels mark metabolic and functional impairment in advanced COPD. Thorax 2006; 61: 17-22.

20 Donaldson GC, Seemungal TA, Patel IS, et al. Airway and systemic inflammation and decline in lung function in patients with COPD. Chest 2005; 128: 1995-2004.

21 Gislason T, Olafsdottir IS, Thjooleifsson B, et al. HsCRP is associated with COPD and a faster decline in $\mathrm{FEV}_{1}-\mathrm{a}$ multicentre epidemiological study. Eur Respir J 2005; 26: Suppl. 49, 51s.

22 Kony S, Zureik M, Driss F, Neukirch C, Leynaert B, Neukirch F. Association of bronchial hyperresponsiveness and lung function with C-reactive protein (CRP): a population based study. Thorax 2004; 59: 892-896.

23 Ridker PM. High-sensitivity C-reactive protein, inflammation, and cardiovascular risk: from concept to clinical 
practice to clinical benefit. Am Heart J 2004; 148: Suppl. 1, S19-S26.

24 Pauwels RA, Löfdahl CG, Laitinen LA, et al. Long-term treatment with inhaled budesonide in persons with mild chronic obstructive pulmonary disease who continue smoking. European Respiratory Society Study on Chronic Obstructive Pulmonary Disease. N Engl J Med 1999; 340: 1948-1953.

25 World Health Organization. 1991 World Health Statistics Annual. Geneva, World Health Organization, 1992.

26 Kiechl S, Werner P, Egger G, et al. Active and passive smoking, chronic infections, and the risk of carotid atherosclerosis. Prospective results from the Bruneck Study. Stroke 2002; 33: 2170-2176.

27 Sin DD, Man SF. Can inhaled steroids mend a broken heart in chronic obstructive pulmonary disease? Eur Respir J 2005; 4: 589-590.

28 Wei L, MacDonald TM, Walker BR. Taking glucocorticoids by prescription is associated with subsequent cardiovascular disease. Ann Intern Med 2004; 141: 764-770.
29 Wedzicha JA, Seemungal TA, MacCallum PK, et al. Acute exacerbations of chronic obstructive pulmonary disease are accompanied by elevations of plasma fibrinogen and serum IL-6 levels. Thromb Haemost 2000; 84: 210-215.

30 Calverley PMA. Reducing the frequency and severity of exacerbations of chronic obstructive pulmonary disease. Proc Am Thorac Soc 2004; 1: 161-166.

31 Calverley P, Pauwels R, Vestbo J, et al. Combined salmeterol and fluticasone in the treatment of chronic obstructive pulmonary disease: a randomised controlled trial. Lancet 2003; 361: 449-456.

32 Burge PS, Calverley PM, Jones PW, Spencer S, Anderson JA, Maslen TK. Randomised, double blind, placebo controlled study of fluticasone propionate in patients with moderate to severe chronic obstructive pulmonary disease: the ISOLDE trial. BMJ 2000; 320: 1297-1303.

33 Johnell $\mathrm{O}$, Pauwels R, Lofdahl CG, et al. Bone mineral density in patients with chronic obstructive pulmonary disease treated with budesonide Turbuhaler. Eur Respir J 2002; 19: 1058-1063. 